\title{
Chapter X. A Choice Experiments Application in Transport Infrastructure: A Case Study on Travel Time Savings, Accidents and
}

\section{Pollution Reduction}

\author{
Phoebe Koundouri
}

Athens University of Economics and Business

Yiannis Kountouris

University of Manchester

\author{
Mavra Stithou \\ University of Stirling
}

\begin{abstract}
This paper presents the results of a Choice Experiment (CE) conducted to estimate the values derived from a highway construction project in Greece. To account for preference heterogeneity conditional logit with interactions and random parameter logit models are estimated. The results indicate that individuals have significant values for travel time savings, percentage decrease in traffic accidents, percentage decrease in traffic related emissions and landscape modifications. Models where the attributes are interacted with socioeconomic variables perform better and produce lower welfare estimates compared to models without interactions with important implications for cost benefit analysis.
\end{abstract}

\section{Introduction and Motivation}

Performing accurate cost-benefit analysis is a challenging task for policy making especially for the evaluation of public infrastructure projects. Such projects involve use 
and non-use values resulting from many alternative motivations. Due to market failures or the outright lack of markets and market prices many of the values cannot be estimated using revealed preference data. Without accurate and efficient estimates for the entirety of the generated values there is a risk of underestimating the benefits accrued to the public by the project hence under-providing the public good.

Especially when estimating the benefits from new highway construction, important values enter the scope of the analysis. These values relate to individual well-being, environmental conditions as well as impacts on the landscape. Specifically, there exist benefits generated from the decrease in the number of serious traffic accidents in the locality of the new highway. Additional values can also result from environmental improvements due to reduced emissions from vehicles. Furthermore, any construction involves landscape modification that should be fully accounted for in the cost benefit analysis. For the purpose of cost benefit analysis, values generated form decreased accident rates are often approximated using the human capital approach according to which the value of an accident foregone is given by the present value of the expected income flow had the accident not happened. While this approximation may accommodate the marginal value of one less accident at the macro level, it fails to recognize values accruing to the individual that emerge from altruistic motives, thus excluding them from the analysis. Benefits from reduction in traffic related emissions are similarly evaluated using monetary estimates on the environmental damage caused by emissions without accounting for non-use, bequest and altruistic values. This approach is inappropriate from 
the economist's point of view, according to which values should be derived from individual preferences.

In order to estimate the values involved in public construction projects accurately, it is important to evaluate all non-use benefits and explicitly account for them in cost benefit analysis. Hence, it is necessary to circumvent the lack of prices for non-marketed characteristics like travel time savings, percentage accident and emissions reduction and landscape impacts by applying non market valuation methods that are based on the creation of hypothetical markets using stated preference data.

Recent literature on the estimation of benefits from the reduction of accident rates includes Iragüen and Dios Ortuzar (2004) who apply a CE to estimate the Willingness-toPay (WTP) for reducing fatal accident risk in urban areas. Regarding the valuation of travel time savings Hensher (2001) estimates the value from decreased travel times in New Zealand using mixed logit models. A CE approach is also followed in the valuation of travel time by Amador et al. (2005) who explicitly account for preference heterogeneity for when evaluating the benefits accruing to the public from travel time savings. On the effects of policy measures Garrod et al. (2002) estimate the effects of traffic calming to the UK population.

In this paper we present the results of a CE aiming to value different characteristics relating to the construction of a public highway in Greece. To inform policy making, valuations for travel time savings, landscape impacts, as well as percentage decreases in 
accidents and emissions are estimated. Next section introduces the case study. Third section presents the CE method and the theoretical grounding of the models estimated, while section four discusses the survey design and implementation. Section five presents the results and last section concludes the paper.

\section{The Case Study}

This paper draws on data from a case study regarding the construction of a new highway under consideration that will connect mainland Greece with the island of Evia. The island of Evia is located to the east of mainland Greece and the distance between them at some points is less than 500 meters. This has led to efforts to connect the two land masses to facilitate quick transport with land transportation means. At the moment there are three alternative ways to reach Evia form mainland Greece: the “old” and “new” bridges connecting mainland Greece and Chalkida the capital of the island and ferry services traveling between mainland Greece and Evia.

The proximity of Chalkida to Athens, the largest city in Greece which lies $80 \mathrm{~km}$ to the south, is an important factor that necessitates the improvement of the local road network. Traffic in the surrounding areas has increased in recent years as the numbers of commuters living in Evia and working in Athens and vice versa increased. In addition, Evia is a popular holiday and weekend destination for residents of Athens. The overall increase in traffic results in severe congestion in Chalkida, the main entry point to the island. The state of the local road network is not sufficient for current needs and is deteriorating. These effects have lead policy makers to explore alternative measures to 
decongest Chalkida and replace sections of the existing aging infrastructure. The solution proposed is the development of a new highway connecting mainland Greece and Evia that will be completed by 2013.

The highway is planned to connect Schimatari in mainland Greece with Aghios Nickolaos in Evia. The new highway will be located to the south of the existing bridges and will facilitate traffic towards southern and northern Evia bypassing the city of Chalkida, and circumventing sections of the existing network thus reducing travel times and accident rates. The main beneficiaries from the development are expected to be local residents as well as the recreational and business travelers to Evia.

\section{The Choice Experiment Method}

CEs have been widely applied during the past decade in the fields of environmental, resource, health and transportation economics (see for example, Hanley et al., 2002; Birol et al., 2006; Garrod et al., 2002) for the estimation of public goods' use and non use values. The theoretical foundations of the CE method lie on Lancaster's characteristics theory of value according to which individuals derive utility from the characteristics composing the good instead from the good as a whole (Lancaster, 1966). The theoretical basis for incorporating stated behavior with economic valuation is provided by the random utility theory (McFadden, 1974). 
The most popular econometric specification for the analysis of CE data to date continues to be the Conditional Logit Model (CLM) (McFadden, 1974). In the random utility framework the utility of respondent $i$ from choosing alternative $j$ is given by:

$$
U_{i j}=V_{i j}\left(Z_{i j}\right)+e_{i j} \quad \ldots
$$

where for any household $i$ is the respondent, $(Z)$ the alternative, $V$ is the deterministic component of utility, $e$ is the non-systemic component of utility and $Z$ are the attributes of the good to be valued. The deterministic component of utility represents the impacts on utility that the researcher can observe while the random component corresponds to all effects unobserved by the researcher. Assuming that the relationship between utility and attributes is linear in the parameters and variables function, and that the error terms are identically and independently distributed with a Type 1 extreme value distribution, the probability of any particular alternative $j$ being chosen can be expressed in terms of a logistic distribution. Equation (1) can be estimated with a conditional logit model (McFadden, 1974; Greene, 2000), which takes the general form:

$$
P_{i j}=\frac{\exp \left(V\left(Z_{i j}\right)\right)}{\sum_{h=1}^{C} \exp \left(V\left(Z_{i h}\right)\right)} \quad \ldots
$$

where the conditional indirect utility function generally estimated is:

$$
V_{i j}=\beta_{1} Z_{1}+\beta_{2} Z_{2}+\ldots \ldots+\beta_{n} Z_{n} \quad \ldots
$$

Where $n$ is the number of attributes considered, and the vectors of coefficients $\beta_{1}$ to $\beta_{n}$ are attached to the vector of attributes $(Z)$. 
In recent years however there has been increasing dissatisfaction with the CLM, since in effect it imposes homogeneous preferences across individuals, unless these can be adequately represented using interactions with observable socio-economic characteristics. Furthermore, the CLM does not allow for error correlation across respondents' choices. This can lead to biased estimation of the WTP. As Hensher (2001) notes the CLM can result in the underestimation of the value of travel time savings. This shortcoming of the conditional logit model has seen the development of alternative models relaxing the preference heterogeneity restriction such as the Random Parameter Logit model (RPL) (Train, 1998).

In the RPL model preference heterogeneity is considered to affect the systematic component of utility at the individual level. Then, heterogeneity is accounted for by assuming that the attribute coefficients in the estimated model are distributed across respondents. The estimated coefficients represent the mean of the parameter distributions. Specifically, the utility derived by individual $i$ from alternative $j$ is given by

$$
U_{i j}=\beta X_{i j}+\psi_{i} X_{i j}+\varepsilon_{i j} \quad \ldots
$$

where $X_{i j}$ is the vector of attributes and $\beta$ is the vector of coefficients associated with the attributes. The derivation of different parameters for each individual is made possible by the inclusion of the vector of deviation parameters $\psi_{i}$. Assuming that the error term $\varepsilon_{i j}$ is iid with Type 1 extreme value distribution, the probability that individual $i$ chooses alternative $j$ is given by calculating the integral 


$$
\operatorname{Pr}_{i j}=\int \frac{\exp \left(\beta_{i} X_{i j}\right)}{\sum_{n=1}^{N} \exp \left(\beta_{i} X_{i n}\right)} f\left(\beta_{i} \mid \theta\right) \mathrm{d}\left(\beta_{i}\right) \quad \ldots
$$

with $N$ being the number of alternatives in each choice set and $\theta$ the distribution parameters. The integral in equation 5 does not have a closed form solution and should be calculated with simulation methods.

\section{Survey Design and Administration}

To design a CE survey it is essential to identify the good to be valued and express it in terms of a finite number of characteristics. The public good to be valued in this case was the new highway. The attributes and their levels were chosen with the consultation of engineers developing the project and focus groups with the general public. Furthermore, the attributes were selected to reflect the effects of the highway in the population of Evia and the surrounding areas as well as satisfy the guidelines of the Greek ministry of Environment and Public Works for cost-benefit analysis. We opted for a small scale experimental design since initial testing and focus groups revealed that respondents were extremely adverse to longer questionnaires. The attributes and their corresponding levels are presented in table 1.

\begin{tabular}{|l|l|l|}
\hline Table 1: Attributes and their Levels. \\
\hline Attribute & Levels & Status Quo \\
\hline Time Saving & 5 minutes, 10 minutes & No time saving \\
\hline Percentage Decrease in Accidents & $30 \%$ reduction, $60 \%$ reduction & No change \\
\hline Percentage Decrease in Emissions & $30 \%$ reduction, $70 \%$ reduction & No change \\
\hline Type of Crossing & Bridge, Tunnel & No crossing \\
\hline Toll & $€ 0.5, € 1, € 1.2, € 1.5$ & $€ 0$ \\
\hline
\end{tabular}

The attributes relate to the expected impacts of the new highway to the general public as a result of decreased traveling distances bypass of hazardous locations of the existing 
road network. The travel time saving attribute refers to the average time required for individuals to reach the national road network from any of the locations that will be served from the highway. It was estimated by the engineers involved in the construction that depending on its exact layout, the highway could save travelers 5 or 10 minutes for reaching the national road network. The new highway is expected to decrease the number of serious accidents, defined as those resulting to injury or death. Depending on the layout of the road it is expected that accidents will decrease by $30 \%$ or by $60 \%$. The new layout will decrease emissions from cars in the area by $30 \%$ or $70 \%$. The type of crossing attribute refers to the mode of the axis while crossing the sea between mainland Greece and the island of Evia. For the length of 600 meters the crossing can cross over the sea on a bridge or below the sea in a tunnel. This attribute was chosen to explore the public's preferences with regards to the effects of the construction on the landscape. A tunnel construction was perceived to minimize the interference to the landscape. The monetary attribute was defined as the toll rate per crossing, a charge that would be levied to all users of the highway. This choice was motivated by its familiarity with the respondents and its credibility among them. The levels of the toll rate attribute where selected to emulate 2007 charges in the Greek national and local road network with the purpose of improving the credibility of the constructed scenarios.

Based on these attributes and their levels a number of scenarios can be constructed. Following an orthogonalization procedure (Louviere et al., 2000), thirty two unique profiles were developed. These were randomly paired in choice sets. In particular, a foldover with random pairing approach was followed. Providing all sixty four scenarios 
in a single task was not feasible and hence the number of scenarios was reduced to sixteen by designing one version based on the orthogonal main effects plan. Then, a second statistically equivalent version constructed from the "foldover" of the first version resulted in the final thirty two scenarios that were considered adequate to allow estimation of all the parameters of interest. It should be noted that same approach has been also applied in Coast et al. (2008) and Hjelmgren and Anell (2007). The choice sets were assigned to four different versions consisting of four choice sets each. Each choice set was complemented with an additional profile describing the status quo expressed by the attributes at their current levels. The inclusion of the status quo is necessary for the welfare interpretation of the WTP estimates (Bateman et al., 2003). Table 2 presents an example of a choice set.

\begin{tabular}{|l|l|l|l|l|l|l|}
\hline \multicolumn{2}{|l|}{ Table 2: Example of a Choice Set. } \\
\hline Please tell us which of the layouts presented below you prefer. \\
\hline & Layout 1 & & Layout 2 & & No New Road \\
\hline Time Saving & & 10 minutes & & 10 minutes & & No time saving \\
\hline $\begin{array}{l}\text { Car Accidents } \\
\text { Reduction }\end{array}$ & $30 \%$ & & $30 \%$ & & No reduction \\
\hline $\begin{array}{l}\text { Noise and Pollution } \\
\text { Reduction }\end{array}$ & $70 \%$ & & $30 \%$ & & No change \\
\hline Type of Crossing & & Bridge & & Bridge & & No crossing \\
\hline Toll & $€ 1.2$ & & $€ 1$ & & No toll \\
\hline
\end{tabular}

The survey instrument started by introducing the organizations participating in the construction project and guaranteeing the anonymity and confidentiality of the responses. Subsequently respondents were presented with details regarding the new highway. These included an accurate description of the attributes and the levels used in the CE design as well as a map visualizing in broad lines the proposed layout of the new highway. Before 
posing any question to the respondents, they were reminded of the substitute goods and were asked to keep in mind payments their household makes for similar goods and services.

Once the details regarding the project were explained, the respondents were guided through the four choice sets and where asked to state their preferences among the two alternative layouts and the status quo. Follow-up questions were asked to those selecting the status quo alternative in order to identify protestors. Further questions collected information on car ownership, number of cars owned and whether there was a professional driver in the respondent's household. Questions that assessed the driving habits of the respondents and their expectations regarding their usage of the new highway were also asked. Finally, the survey concluded with the collection of socioeconomic data, such as age, household size education level and income.

The CE survey was implemented using face to face interviews of randomly intercepted individuals in various locations in the island Evia and in Athens in June 2007. These locations were chosen in order to approach a sample of the population that is interested in traveling to Evia and may also derive use and non-use values from the project's construction. In total 150 in-person interviews were completed with a response rate of approximately $78 \%$. Among the respondents four protestors were identified and removed from the sample.

\section{Results}


Table 3 presents the descriptive statistics of the sample.

\begin{tabular}{|l|l|l|}
\hline Table 3: Descriptive Statistics. & Mean & Std Dev \\
\hline Variable & 0.868 & 0.339 \\
\hline Driver (1=yes, 0=no) & 0.980 & 0.243 \\
\hline $\begin{array}{l}\text { Car owner in household (1=yes, } \\
0=\text { no })\end{array}$ & 0.204 & 0.404 \\
\hline $\begin{array}{l}\text { Professional driver in household } \\
(1=y e s, 0=\text { no })\end{array}$ & 0.414 & 0.494 \\
\hline Live $(0=$ Evia,1=Elsewhere) & 0.517 & 0.501 \\
\hline Work(0=Evia,1=Elsewhere) & 0.743 & 0.438 \\
\hline $\begin{array}{l}\text { Employment (1=in full employment, } \\
0=\text { other) }\end{array}$ & 0.356 & 0.480 \\
\hline $\begin{array}{l}\text { Education (1=university education } \\
\text { and above, } 0=\text { less that university } \\
\text { education) }\end{array}$ & & \\
\hline Gender (1=male,0=female) & 0.72 & 0.451 \\
\hline Age & 40.068 & 13.901 \\
\hline Car number in household & 2.099 & 1.254 \\
\hline Household monthly income $(€)$ & 2439.85 & 1240.933 \\
\hline Household size & 3.738 & 1.407 \\
\hline
\end{tabular}

Approximately $87 \%$ of the individuals interviewed are registered drivers while $20 \%$ of the respondents live in households with professional drivers. Over $98 \%$ of the respondents live in a car owing household while the average car ownership is 2 cars per household. $74 \%$ of the sample is in full time employment while $35 \%$ have completed or are in the process of completing their university education. Regarding the residence and workplace of the respondents, $41 \%$ and $51 \%$ of the sample reside and work outside of Evia respectively.

For the econometric analysis the impacts of the highway construction on travel time savings, percentage accident reduction, percentage pollution reduction and toll rate entered the analysis as continuous variables while two dummy variables indicated the type of crossing using no crossing as the baseline level. To test for preference heterogeneity we carried out a Hausman (1978) test. Table 4 presents the results of the test for the IIA property. The test was carried out by removing one of the three alternative 
choices from the respondents' choice sets. The IIA assumption is rejected for the first case while the Hausman statistic cannot be calculated for the second and third case as a result of the existence of non-positive definite matrix. Greene (2002) notes that it is possible when you drop one or more alternatives some attribute to be constant among the remaining choices leading to singularities. The rejection of the IIA assumption implies that applying the usual conditional logit model could lead to misleading results and alternative, less restrictive models should be applied (Birol et al., 2006; Hanley et al., 2006). To take into account of the potential preference heterogeneity in addition to the standard CLM we present the results of the CLM with interactions and the RPL model with and without interactions.

\begin{tabular}{|c|c|c|}
\hline Table 4: Results of the Hausman Test for IIA. \\
\hline Excluded Choice & Statistic & Significance level \\
\hline Scenario A & 25.531 & 0.0003 \\
\hline Scenario B & \multicolumn{2}{|c|}{ Could not be carried out } \\
\hline Scenario C & \multicolumn{2}{|c|}{ Could not be carried out } \\
\hline
\end{tabular}

\section{Conditional Logit Model}

The results of the CLM are presented in the first column of table 5. The estimated parameters on all attributes included in the model are statistically significant, thus affecting individual scenario choice. All parameters have the expected signs. The coefficient on travel time savings is positive implying that individuals are more likely to choose alternatives with higher travel time savings. This is also the case for the coefficient on percentage pollution reduction: the probability of selecting an alternative increases with the percentage decrease in pollution. The positive parameter on the percentage accident decrease attribute indicates that respondents prefer scenarios with lower accident rates. The coefficients on the two crossing dummy variables are also 
positive indicating that building some type of crossing is more desirable that no crossing at all. Furthermore, the magnitude of the two coefficients is almost identical. Consequently, respondents in general do not have a distinct preference for either one of the two proposed crossings and can be considered to be indifferent between the two. Finally the coefficient on the monetary payment attribute is negative conforming to economic theory since higher toll rates decrease the probability that an alternative is selected.

The highest effect on utility results from the accident reduction attribute, followed by bridge and tunnel construction. Pollution decrease has the third highest magnitude while the smallest impact on utility comes from travel time savings.

\section{Conditional Logit Model with Interactions}

To capture possible preference heterogeneity that is attributed to observable socioeconomic factors for different highway construction we estimate a conditional logit model including some of the respondent's socioeconomic characteristics as interaction terms with the highway construction attributes. After extensive testing among interaction terms, we found the best fitting model to be the one including the following interactions: a dummy variable indicating whether the respondent resides away from Evia interacted with the percentage decrease in accidents and the tunnel attributes, the number of cars belonging to the respondent's household interacted with the accident reduction and the toll rate and finally a dummy variable indicating whether the respondent is in full-time 
employment interacted with the toll rate. The results of the CLM with interactions are reported in the second column of table 5.

Regarding the attribute coefficients, they remain significant and maintain the same signs as in the original CLM specification. Nevertheless, the coefficients are now of slightly different magnitude. Respondents that reside away from Evia are more likely to select alternatives with higher decrease in accidents relative to those that reside in the vicinity. This could be attributed to individuals not living in the area overestimating the numbers of serious accidents, even though this information was conveyed in the survey. Furthermore respondents that do not live in Evia are more likely to select the tunnel construction. This implies that the local population is relatively more adverse to the least intrusive method of construction. The justification for this effect could be found in the previous experience of local residents with the already existing bridges. These bridges have developed to landmarks for the wider area and locals may foresee additional values from the creation of a new landmark. Non-residents on the other hand derive values relating to the conservation of the local environment as well as from recreation in the area. This could justify their preference for minimal visual intervention. Respondents are more likely to choose alternatives with higher toll rates the larger the number of cars their household owns. This effect appears counterintuitive at first sight since it implies that household expenditure may increase. On the other hand, this may be an indication of the intention of respondents to internalize environmental externalities relating to car use. The interaction of the toll rate with a dummy variable indicating whether the respondent is full time employment though not statistically significant is of the expected positive sign 
indicating that respondents with certain and presumably higher income are willing to pay higher amounts.

To examine whether the model with interactions is an improvement to the standard conditional logit model we perform a Swait-Louviere log likelihood ratio test. The test indicates that there is significant increase to model fit form the CLM with interactions comparing to the original CLM at $1 \%$ significance level.

\section{Random Parameter Logit Model}

For the RPL model specification we assume that preferences are heterogeneous for the travel time saving and pollution attributes. Their parameters are assumed to be normally distributed across the population. Heterogeneity of preferences over travel time savings is motivated from the cross section of individuals that are likely to benefit form the highway that includes leisure travelers, local residents, commuters and others that are likely to have different preferences on travel time. Regarding pollution reduction, preference heterogeneity was considered after focus groups indicated that residents and nonresidents of the affected areas had different perceptions about the acceptable levels of emissions in the area. Table 5 presents the results of the best fitting random parameter logit model.

\begin{tabular}{|l|l|l|l|l|l|}
\hline Table 5: RPL and CL Models Estimation. & $\begin{array}{l}\text { Random } \\
\text { Parameter Logit }\end{array}$ & $\begin{array}{l}\text { Random } \\
\text { Parameter Logit } \\
\text { with Interactions }\end{array}$ \\
\hline Variable & $\begin{array}{l}\text { Conditional } \\
\text { Logit Model }\end{array}$ & $\begin{array}{l}\text { Logit Model } \\
\text { with } \\
\text { Interactions }\end{array}$ & Coefficient & Coefficient \\
\hline & Coefficient & Coefficient & & Coent & \\
\hline
\end{tabular}




\begin{tabular}{|c|c|c|c|c|c|}
\hline Travel Time Savings & $\begin{array}{l}0.063 * * \\
(0.028)\end{array}$ & $\begin{array}{l}0.059 * * \\
(0.028)\end{array}$ & & $\begin{array}{l}0.107 * * \\
(0.051) \\
\end{array}$ & $\begin{array}{l}0.102 * * \\
(0.053)\end{array}$ \\
\hline $\begin{array}{l}\text { Percentage Decrease } \\
\text { in Accidents }\end{array}$ & $\begin{array}{l}2.030 * * * \\
(0.440)\end{array}$ & $\begin{array}{l}2.436 * * * \\
(0.913)\end{array}$ & & $\begin{array}{l}2.545 * * * \\
(0.633)\end{array}$ & $\begin{array}{l}2.967 * * * \\
(1.247)\end{array}$ \\
\hline $\begin{array}{l}\text { Percentage Decrease } \\
\text { in Pollution }\end{array}$ & $\begin{array}{l}0.995 * * * \\
(0.294)\end{array}$ & $\begin{array}{l}1.062^{* * *} \\
(0.300)\end{array}$ & & $\begin{array}{l}1.696 * * \\
(0.667)\end{array}$ & $\begin{array}{l}1.671^{* * *} \\
(0.633)\end{array}$ \\
\hline Bridge & $\begin{array}{l}1.929 * * * \\
(0.450)\end{array}$ & $\begin{array}{l}2.002 * * * \\
(0.448)\end{array}$ & & $\begin{array}{l}4.296 * * * \\
(1.483)\end{array}$ & $\begin{array}{l}4.424^{* * *} \\
(1.644)\end{array}$ \\
\hline Tunnel & $\begin{array}{l}1.878 * * * \\
(0.441)\end{array}$ & $\begin{array}{l}1.798 * * * \\
(0.463)\end{array}$ & & $\begin{array}{l}4.220 * * * \\
(1.458)\end{array}$ & $\begin{array}{l}4.134^{* * *} \\
(1.584)\end{array}$ \\
\hline Toll & $\begin{array}{l}-0.455^{* * * *} \\
(0.171)\end{array}$ & $\begin{array}{l}-1.209 * * * \\
(0.409)\end{array}$ & & $\begin{array}{l}-0.594^{* * *} \\
(0.216)\end{array}$ & $\begin{array}{l}-1.578^{* * *} \\
(0.563)\end{array}$ \\
\hline $\begin{array}{l}\text { Percentage Decrease } \\
\text { in Accidents*Live } \\
\text { away from Evia }\end{array}$ & & $1.283 *(0.768)$ & & & $\begin{array}{l}1.765 \\
(1.121)\end{array}$ \\
\hline $\begin{array}{l}\text { Tunnel*Live away } \\
\text { from Evia }\end{array}$ & & $\begin{array}{l}0.375^{*} \\
(0.211) \\
\end{array}$ & & & $\begin{array}{l}0.498 * \\
(0.299)\end{array}$ \\
\hline $\begin{array}{l}\text { Percentage Decrease } \\
\text { in Accidents*Car } \\
\text { number }\end{array}$ & & $\begin{array}{l}-0.409 \\
(0.305)\end{array}$ & & & $\begin{array}{l}-0.522 \\
(0.411)\end{array}$ \\
\hline Toll*Car number & & $0.244 * *(0.125)$ & & & $\begin{array}{l}0.296 * \\
(0.161) \\
\end{array}$ \\
\hline $\begin{array}{l}\text { Toll*In full time } \\
\text { employment }\end{array}$ & & $0.265(0.321)$ & & & $\begin{array}{l}0.425 \\
(0.433)\end{array}$ \\
\hline & & & \multicolumn{3}{|c|}{ Derived Standard deviations } \\
\hline & & & $\begin{array}{l}\text { Travel Time } \\
\text { Savings }\end{array}$ & $\begin{array}{l}0.211^{*} \\
(0.127) \\
\end{array}$ & $\begin{array}{l}0.229 * \\
(0.141)\end{array}$ \\
\hline & & & $\begin{array}{l}\text { Percentage } \\
\text { Pollution } \\
\text { Decrease }\end{array}$ & $\begin{array}{l}4.922 * * \\
(2.015)\end{array}$ & $\begin{array}{l}4.505 * * \\
(1.937)\end{array}$ \\
\hline \multicolumn{6}{|c|}{ Standard errors in parenthesis. } \\
\hline $\mathrm{R}^{2}$ & 0.35599 & 0.365 & & 0.361 & 0.369 \\
\hline Log-likelihood & -413.192 & -407.635 & & -410.062 & -404.523 \\
\hline $\begin{array}{l}\text { Restricted Log- } \\
\text { likelihood }\end{array}$ & -641.589 & -641.589 & & -641.589 & -641.589 \\
\hline
\end{tabular}

The estimated parameters on all attributes included in the model are statistically significant, thus affecting individual scenario choice. Furthermore, all estimated coefficients carry the expected sign as was the case for the CLM, suggesting that the respondent is more likely to select an alternative the higher the level of travel time savings, percentage of accidents and pollution reduction. On the other hand respondents are less likely to select alternatives with higher toll rates. Comparing to the CLM model, the estimated coefficients of the RPL model are of noticeably higher magnitude. 
Indicatively the coefficients on the type of construction dummies are of twice the magnitude of the same coefficients under the CLM.

The significant derived standard deviation of the travel time savings and percentage reduction in pollution attributes suggests that there exists heterogeneity in preferences for these attributes. The magnitude of the derived standard deviation in both cases is such that it implies that there exist respondents with negative preferences for travel time savings and percentage decrease in pollution. Specifically, $30.63 \%$ of the respondents have negative preferences for travel time savings while $36.52 \%$ are more likely to select alternatives with lower percentage pollution decrease.

Among the attributes valued in the study, the dummy variables indicate the type of crossing have the strongest effect on utility. This illustrates the desire of the respondents to move away from the status quo of no crossing between Athens and Evia in this particular area. The next highest effect on utility is derived from percentage decrease in accidents. This suggests that respondents have significant values that are based on self preservation and altruistic motives. Percentage reduction in pollution also has substantial impact on the likelihood of an alternative's choice. Among the positive impacts on utility travel time savings have the smallest impact on alternative choice.

\section{Random Parameter Logit with interactions}

The results of the RPL model with interactions are presented in the fourth column of table 5. As in the CL model with interactions we observe a minor change in the 
magnitude of the coefficients on attributes. The coefficients of the interaction terms maintain the signs of the CL with interactions models. Nevertheless now the interaction of accident decrease with the dummy indicating residence location is no longer significant. The derived standard deviations are still significant and imply that $32.8 \%$ of the respondents have negative preference for travel time savings while $35.5 \%$ of the respondents are more likely to choose alternatives with lower pollution reduction. Similarly to the CLM case, the Swait-Louviere log-likelihood test reveals that model fit is significantly improved when adding the interaction terms in the model.

\section{Willingness to Pay Estimates}

To derive the marginal WTP for changes in attributes for the CL and the RPL models we apply the formula 6 adjusting it accordingly:

$W T P=-1\left(\frac{\hat{\beta}_{\text {attribute }}}{\hat{\beta}_{\text {payment }}}\right)$

In particular, this formula is employed in the case of a CL model with no interaction terms as well as of an RPL with no interaction terms and no-random variables (type of crossing and percentage decrease in accidents). When interaction terms are also included formula 7 is applied:

$W T P_{\text {attribute }}=-1\left(\frac{\hat{\beta}_{\text {attribute }}+\hat{\beta}_{\text {socdem.var.attribute }} \cdot \text { Socdem.Var }}{\hat{\beta}_{\text {payment }}+\hat{\beta}_{\text {socdem.var.payment }} \cdot \text { Socdem.Var }}\right)$

In particular, we obtain the numerator of WTP by deriving utility with respect to the attributes, that is, generally, $\hat{\beta}_{\text {attribute }}+\hat{\beta}_{\text {socdem.var.attribute }} \cdot$ Socdem.Var which depends on a specific value of the socioeconomic variable. Similarly, the denominator of WTP is 
obtained by deriving utility with respect to payment, as $\hat{\beta}_{\text {payment }}+\hat{\beta}_{\text {socdem.var.payment }}$. Similar expressions were obtained by Galilea and Ortúzar (2005) and Hoyos et al. (2009). In the presence of an RPL model specification WTP estimates need to take into account as well the randomness of the identified random parameters (time saving and percentage decrease in emissions parameters). Hence, considering formula 6 but with $\hat{\beta}_{\text {atribute, }}$ and specifying the cost parameter as non-random allows easy derivation of the distribution of WTP for each attribute, since it is distributed in the same way as the attribute's parameter (Revelt and Train, 2000). As a result, simulated distributions of WTP are obtained. This approach was also adopted in Westerberg et al. (2010).

Table 6 reports the WTP estimates for the attributes under the CLM, the RPL and their corresponding versions with interactions, for the average respondent.

\begin{tabular}{|c|c|c|c|c|}
\hline Attribute & $\begin{array}{l}\text { Conditional } \\
\text { Logit }\end{array}$ & $\begin{array}{c}\text { Random Parameter } \\
\text { Logit }\end{array}$ & $\begin{array}{c}\text { Conditional Logit } \\
\text { with Interactions - } \\
\text { Average Profile }\end{array}$ & $\begin{array}{c}\text { Random } \\
\text { Parameter Logit } \\
\text { with Interactions- } \\
\text { Average Profile }\end{array}$ \\
\hline Travel time savings & $\begin{array}{l}0.139 \\
(0.091)\end{array}$ & $\begin{array}{l}0.180 * * \\
(0.106)\end{array}$ & $\begin{array}{r}-0.660^{*} \\
(0.379)\end{array}$ & $-0.873 *(0.509)$ \\
\hline $\begin{array}{l}\text { Percentage Accident } \\
\text { Reduction }\end{array}$ & $\begin{array}{l}4.459 * * \\
(1.789)\end{array}$ & $\begin{array}{l}4.288^{* *} \\
(1.700)\end{array}$ & $\begin{array}{l}-4.386 * * * \\
(1.333)\end{array}$ & $\begin{array}{l}-5.331^{* * *} \\
(1.729)\end{array}$ \\
\hline $\begin{array}{l}\text { Percentage Pollution } \\
\text { Reduction }\end{array}$ & $\begin{array}{r}2.185^{* *} \\
(0.915)\end{array}$ & $\begin{array}{l}2.857 * * \\
(1.300)\end{array}$ & $\begin{array}{l}0.169 \\
(0.687)\end{array}$ & $\begin{array}{l}0.121 \\
(0.860)\end{array}$ \\
\hline Tunnel & $\begin{array}{l}4.125 * * * \\
(1.486)\end{array}$ & $\begin{array}{l}7.109 * * \\
(2.878)\end{array}$ & $\begin{array}{l}-2.379 * * * \\
(0.628)\end{array}$ & $\begin{array}{l}-4.942 * * * \\
(1.780)\end{array}$ \\
\hline Bridge & $\begin{array}{l}4.237 * * * \\
(1.534)\end{array}$ & & $\begin{array}{l}0.946 \\
(0.939)\end{array}$ & $\begin{array}{l}1.866 \\
(1.451)\end{array}$ \\
\hline
\end{tabular}


It should be noted that while for the models without interactions the all WTP estimates are positive. This is not true for the WTP of the average respondent in the models with interactions. Indicatively, while the WTP for travel time savings in positive for the CLM and RPL models while it becomes negative for the average respondent.

Table 6 illustrates the importance of model selection in our CE application. The differences in the valuation estimates indicate that the results of cost benefit analysis may vary depending on the model selected to describe preferences. Relying on the models without interactions will produce higher benefits regarding the project in question. However, as reported earlier, the models with interactions perform significantly better compared to their counterparts that contain no interactions. As a result, ignoring possible socioeconomic factors that may influence individual valuation may eventually lead to the overestimation of the benefits and ultimately to false conclusions to the cost-benefit analysis.

\section{Conclusions}

In this paper we presented the results of a CE designed to provide estimates of the value for alternative characteristics of highway construction in Greece. The values identified to be significant in such a construction related to the effects on environment, individual and general well being, landscape and travel time. With this motivation the attributes chosen for the purposes of the analysis related to the decrease in travel time, the expected decrease in accident rates and emissions as well as the type of the construction in terms of its effects on the visual amenity of the area. Some preference heterogeneity was identified 
and accounted for with including socioeconomic factors in the models as well as by estimating random parameter models. The results indicate that respondents derive significant values from all attributes we employ in this study, under all estimated models. However there are noticeable differences in the estimated values under the alternative models estimated.

\section{References}

Amador, J.A., Gonzalez, R.M., \& De Dios Ortuzar, J. (2005). Preference heterogeneity and willingness to pay for travel time savings. Transportation, 32, 627-647.

Bateman, I.J., Carson, R.T., Day, B., Hanemann, W.M., Hanley, N., Hett, T., Jones-Lee, M., Loomes, G., Mourato, S., Ozdemiroglu, E., Pearce, D.W., Sugden, R. \& Swanson, S. (2003). Guidelines for the Use of Stated Preference Techniques for the Valuation of Preferences for Non-market Goods. Cheltenham, UK: Edward Elgar.

Birol, E., Karousakis, K., \& Koundouri, P. (2006). Using a choice experiment to account for preference heterogeneity in wetland attributes: The case of Cheimaditida wetland in Greece. Ecological Economics, 60 (1), 145-156.

Coast, J. Flynn, T. N., Natarajan, L., Sproston, K., Lewis, J., Louviere, J.J., Peters, T. J. (2008). Valuing the ICECAP capability index for older people. Social Science and Medicine, 67, 874-882.

Galilea, P., \& Ortuzar, J.D. (2005). Valuing noise level reductions in a residential location context. Transportation Research Part D Transport and Environment, 10, 305322. 
Garrod, G., Scarpa, R., \& Willis, K., G. (2002). Estimating the Benefits of Traffic Calming on Through Routes: A Choice Experiment Approach. Journal of Transport Economics and Policy, 36, 211-231.

Greene, W.H. (2002). NLOGIT Version 4.0: user's guide. New York, USA: Econometric Software, Inc.

Greene, W.H. (2000). Econometric Analysis (3rd edition). London, UK: Prentice Hall International.

Hanley, N., Colombo, S., Tinch, D., Black, A., \& Aftab, A. (2006). Estimating the benefits of water quality improvements under the Water Framework Directive: are benefits transferable? European Review of Agricultural Economics, 33, 391-423.

Hanley, N., Wright, R.E., \& Koop, G. (2002). Modelling recreation demand using choice experiments: rock climbing in Scotland. Environmental and Resource Economics, 22, 449-466.

Hausman, J., \& McFadden, D. (1984). Specification Tests for the Multinomial Logit Model. Econometrica, 52, 1219-1240.

Hausman, J. A. (1978). Specification Tests in Econometrics. Econometrica, 46, 12511271.

Hensher, D. (2001). The valuation of commuter travel time savings for car drivers: evaluating alternative model specifications. Transportation, 28, 101-118.

Hjelmgren J, Anell A. (2007). Population preferences and choice of primary care models: a discrete choice experiment in Sweden. Health Policy, 83(2-3), 314-322. 
Hoyos, D., Mariel, P., \& Fernández-Macho, J. (2009). The influence of cultural identity on the WTP to protect natural resources: Some empirical evidence. Ecological Economics, 68 (8-9), 2372-2381.

Iraguen, P., \& De Dios Ortuzar, J. (2004). Willingness-to-pay for reducing fatal accident risk in urban areas: an Internet-based Web page stated preference survey. Accident Analysis and Prevention, 36 (4), 513-524.

Lancaster, K. (1966). A new approach to consumer theory. Journal of Political Economics, 74, 217-231.

Louviere, J.J., Hensher, D. Swait, J., \& Adamowicz, W. (2000). Stated Choice Methods: Analysis and Applications. Cambridge: Cambridge University Press.

McFadden, D. (1974). Conditional logit analysis of qualitative choice behavior. In: P. Zarembka (Ed), Frontiers in Econometrics (105-142). New York: Academic Press.

Revelt, D. \& Train, K.E. (1998). Mixed logit with repeated choices: households' choices of appliance efficiency level. The Review of Economics and Statistics, 80, 647-657.

Train, K.E. (1998). Recreation demand models with taste differences over people. Land Economics, 74, 230-239.

Westerberg, V.H., Lifran, R., \& Olsen, S.B. (2010). To restore or not? A valuation of social and ecological functions of the Marais des Baux wetland in Southern France. Ecological Economics, 69 (12), 2383-2393. 